\title{
Post-heating response of concrete-filled steel tubular columns under
}

\section{sustained loads}

\author{
C. Ibañez ${ }^{a *}$, L. Bisby ${ }^{b}$, D. Rush ${ }^{b}$, M. L. Romero ${ }^{c}$ and A. Hospitaler ${ }^{c}$ \\ ${ }^{a}$ Department of Mechanical Engineering and Construction, \\ Universitat Jaume I, Castellón, Spain \\ ${ }^{b}$ School of Engineering, University of Edinburgh, UK \\ ${ }^{c}$ Instituto de Ciencia y Tecnología del Hormigón (ICITECH), \\ Universitat Politècnica de València, Valencia, Spain \\ *Corresponding author.e-mail address: ibanezc@uji.es
}

\begin{abstract}
Concrete-filled steel tubular (CFST) columns can generally be expected to better resist elevated temperatures as compared to unfilled steel hollow sections, whose evaluation after a fire is limited by the resulting deformation. A better understanding of the behaviour of CFST columns after a fire, which is dominated by the maximum temperature achieved by the concrete infill and plasticity of the steel, is required to properly estimate their residual strength and deformation and to adopt a reasonable strategy with minimum post-fire repair. In this paper, a fibre beam model for the simulation of the post-heating response of concretefilled steel tubular (CFST) columns is presented. First, the model is validated against experimental results and subsequently it is employed to analyse the post-heating response of circular CFST columns under sustained loads. In reality, during a fire, the columns support load even during the cooling phase of a fire, so it is important to consider this loading condition when predicting the post-fire behaviour. The analysis presented in this paper comprises three stages: heating, cooling and post-fire (under sustained load) conditions. The model considers realistic features typical of the fire response of CFST columns, such as the existence of a gap conductance at the steel-concrete interface and the sliding and separation of
\end{abstract}


the steel tube and the concrete. Based on the model, the response of CFST columns after heating is investigated via parametric analysis.

Keywords: post-heating response; residual capacity; fibre beam model; concrete-filled steel tubular columns; post-fire.

\section{NOTATION}

$A_{c} \quad$ Concrete cross-sectional area

$A_{s} \quad$ Steel cross-sectional area

CFST Concrete-filled steel tube

D Diameter of the steel tube

$f_{c} \quad$ Compressive cylinder strength of concrete

fy $\quad$ Yield strength of structural steel

$N_{\text {ambient }}$ Ultimate capacity at room temperature

$N_{\text {post }} \quad$ Residual capacity at post-heating

No $\quad$ Sustained load for the analysis

$m \quad$ Load ratio for the analysis

$r \quad$ Residual capacity index

$t \quad$ Thickness of the steel tube

$t_{c} \quad$ End of cooling in the analysis

th Heating time for the analysis

$\alpha \quad$ Steel ratio $\alpha=A_{s} / A_{c}$

$\bar{\lambda} \quad$ Relative slenderness 


\section{INTRODUCTION}

In general, steel-concrete composite columns have superior behaviour in fire as compared with unprotected steel structures whose structural evaluation after a fire is reasonably straightforward and is generally limited by fire-induced deformations. Concretefilled steel tubular (CFST) columns demand a more detailed assessment since the concrete infill in such elements is governed primarily by the maximum temperature achieved at any given depth within the cross-section during the fire. Thus, a more complete understanding of the behaviour of CFST columns after fire is required to estimate their residual structural response and capacity. This could enable the development of evidence-based strategies for the post-fire repair and strengthening of CFST columns with minimum cost and downtime.

The available data regarding CFST columns of realistic slenderness, both numerical and experimental, remains limited. Investigations that consider the post-heating phase of the structural response are particularly scarce, and most of these focus only on the residual capacity. No experimental program has yet, to the authors' knowledge, been undertaken on the structural response of CFST columns considering the full heating and cooling phases.

Limited investigations focused on short CFST specimens are available in the literature, and these have informed an understanding of the post-fire residual capacity of such composite columns. For instance, Han et al. [1] presented an experimental program on rectangular CFST columns after exposure to the ISO 834 [2] temperature versus time curve for 90-180 minutes and then loaded to failure at ambient temperature. A numerical model, together with post-fire material models for short CFST columns, was also presented. The authors conclude that an increase in the slenderness ratio and heating phase duration result in a significant decrease of the post-fire response of the columns. Han and Huo [3] continued this investigation with a new experimental campaign on 12 CFST columns, circular and square, which were tested up to failure after exposure to the ISO 834 [2] curve. A numerical model is used to contrast 
experimental results. The authors state that fire exposure increases deflections and decreases the strength of CFST columns.

Huo et al. [4] developed an experimental campaign on short (i.e. stub) columns ( $L / D=1.9-3)$ where the specimens were loaded throughout heating and cooling. However, the finite element model presented was unable to model the cooling phase. It was stated that preloading has a significant influence on the mechanical behaviour of CFST columns, although the failure of the fire-damaged columns remained ductile. The authors also noted that the load and temperature had greater influence on the rigidity of the columns than their capacity.

Following a similar procedure, selected authors of the current paper (Rush et al. [5]) presented the results of a series of post-fire residual compression tests on CFST columns. In contrast to previous papers, some of the columns in this work had higher relative slenderness $(\bar{\lambda}=0.6)$, with a length of $1400 \mathrm{~mm}(L / D=10)$. In this investigation, 19 experiments on unprotected and protected CFST columns, in addition to control tests on six unheated sections, were conducted. The specimens were exposed to fire and then cooled to ambient temperature prior to being tested structurally. Tests were performed including fibre reinforced and high strength concrete in fill, protected and unprotected specimens, and different heating regimes. In addition, a detailed analysis of the cross-sectional temperatures was undertaken [6].

Using cold-formed austenitic stainless steel hollow sections, Tao et al. [7] performed a series of tests on slender CFST columns in fire and after fire exposure. Despite the columns being $1870 \mathrm{~mm}$ long, only the central $880 \mathrm{~mm}$ was exposed to a linear heating regime. The initial imperfection of the specimens and the deformation during the tests were monitored by photogrammetry to study the columns' sensitivity to initial imperfections. A numerical model was presented by the authors but only for the heating stage given the complication of implementing suitable material models for the other stages. 
With regard to numerical models, Yang et al. [8] presented FEM modelling of the entire fire exposure process under loaded conditions, applying the material properties developed by Han et al. [1] for stub columns. However, the interaction mechanisms between the steel tube and the concrete core were not taken into account and the slip existing between the two components, representative of the fire response of CFST columns, was not modelled. This was also pointed out by Song et al. [9] who, aware of the importance of reproducing the interaction between the steel tube and the concrete core, presented a three-dimensional FEM model to predict the fire behaviour and residual capacity of stub CFST columns $(L / D=3)$.

Another FEM model for the behaviour of CFST columns after heating was presented by Yao and $\mathrm{Hu}$ [10]. Again, given the lack of experimental results, the FEM was validated against tests of stub CFST columns that were unloaded while being heated. It was stated that steel recovers most of its strength and stiffness after cooling, but the concrete cannot recover when temperature exceeds $200^{\circ} \mathrm{C}$. The residual capacity was strongly affected by the exposure time, the slenderness ratio, and the diameter. An empirical approach was proposed to calculate the residual strength of post-fire CFST columns.

A general review of the literature shows the lack of experimental and numerical studies for CFST columns, especially for slender members, which consider both heating and cooling under constant loading condition.

In this work, a fibre beam model for the post-heating response of CFST columns is presented which considers realistic features and is intended to reproduce the entire heating and cooling process under load. The model is validated against experiments and, based on the model results, a preliminary parametric analysis of the behaviour of CFST columns after exposure to the overall stage of fire is presented. 


\section{DESCRIPTION OF THE MODEL}

\subsection{General}

The fibre beam model presented herein is based on the FedeasLab [11] platform, a Matlab toolbox for the nonlinear analysis of structures. It was initially developed and validated to predict the fire response of CFST columns [12]-[14] and has now been extended to simulate the post-fire response of such elements.

The model consists of three parts: the concrete core, the steel tube and the link elements, which connect the former two, as shown in Fig. 1. Therefore, a complete circular CFST column is formed by assembling (in parallel) the two components: the steel hollow section and the concrete core. These columns are modelled with fibre finite elements connected at their nodes by link elements both longitudinally and transversely. The fibre beam-column element employed to model the two simple columns has a co-rotational formulation [15].

The interaction rules for the links connecting the elements are designed according to the established behaviour of CFST columns at both room and high temperatures. To assure identical deformed shapes of both components, the transversal link elements have a high stiffness $\left(\mathrm{k}_{\mathrm{t}}=1 \times 10^{15} \mathrm{kN} / \mathrm{m}\right)$. The marginal friction between the steel tube and the concrete core is reproduced by the inner longitudinal links. However, to reproduce the sliding between the concrete core and the steel tube that is known to occur at high temperatures due to their different thermal expansion, the top longitudinal link shows an elevated stiffness under compression $\left(\mathrm{k} 1\right.$,top,comp $\left.=1 \times 10^{15} \mathrm{kN} / \mathrm{m}\right)$ but zero stiffness under tension. The axial load is applied to the top node. This model therefore allows for the free axial elongation of its components; no restraints are needed to model an isolated column. 
In Fig. 1, the cross-sectional discretization pattern adopted after the calibration procedure is shown - this divides the section into a regular array of fibres in both radial and circumferential directions.

\subsection{Material properties}

Heat transfer analysis is undertaken by applying values from EN 1991-1-2 [16]. Gap conductance at the steel-concrete interface is explicitly considered by means of a thermal conductance that reproduces the sudden temperature drop from the steel tube to the concrete core. In this case, a constant value of $200 \mathrm{~W} / \mathrm{m}^{2}$ was employed.

The effect of concrete moisture on the distribution of temperatures is taken into account by assuming that the initial volume of moisture in the concrete starts to evaporate when the temperature reaches $100{ }^{\circ} \mathrm{C}$. During the evaporation all the heat provided is employed in this process so that the temperature does not increase until the moisture has evaporated completely. At elevated temperatures, the thermal properties detailed in [12] are adopted in each case.

\section{Steel}

The temperature dependent mechanical properties recommended in EN 1993-1-2 [17] are implemented for steel. For the post-heating stage, it is assumed that the steel fully recovers its mechanical properties. This implies that both strength and stiffness fully recover their initial ambient temperature values. In addition, it is assumed that steel does not show any residual thermal expansion once it cools down to ambient temperature (i.e. thermal expansion is fully reversible).

For the cooling stage, no suitable evidence-based models are available in the literature. In the current paper, the mechanical model is adapted following the approach of Yang et al. [8], although additional research is needed to corroborate these assumptions. During cooling, 
the stress state of the steel depends not only on the maximum temperature reached during heating $\left(T_{\max }\right)$, but also on the current temperature $(T)$. As shown in Fig. 2, linear interpolation can be applied between two temperature dependent states to determine the current yield strength of steel at a certain temperature $(T)$ during cooling. As can be seen in Fig. 2, those known states correspond to the strain-stress curve at the maximum temperature $\left(T_{\max }\right)$ and to the strain-stress curve at post-heating stage $\left(T_{0}\right)$. The same approach would be applied to obtain the yield strain.

\section{Concrete}

The dependent mechanical properties specified in [12] are adopted for concrete. In this fibre model, for normal strength concrete, the constitutive model developed by Lie [18] was used since it produces a realistic response when modelling the infill of CFST columns in fire. In case of high strength concrete, the model presented by Kodur et al. [19] was employed. In this approach, the concrete tensile strength is ignored. The thermal properties for concrete at elevated temperatures from EN 1992-1-2 [20] were adopted. More data can be found in [12] where the model is described in detail.

Contrarily to steel, concrete suffers irreversible loss of mechanical properties during heating. Therefore, the decrease in the concrete compressive strength as well as the stressstrain relationship post-heating will be given by the maximum temperature reached during heating. Also, since the mechanical properties of concrete are unaffected by the current temperature $T$ at each step of cooling, it is assumed that during this stage the stress-strain relationship is the same as for the post-heating case.

In this work, no additional strength loss for concrete during cooling has been considered, although some works propose this. For example, Eurocode 4 [21] suggests the consideration of an extra loss of $10 \%$ of mechanical properties when modelling concrete after 
a fire. Li and Franssen [22] suggest that this reduction may be even higher, roughly $20 \%$ of the initial compressive strength for temperatures around $500^{\circ} \mathrm{C}$.

In the fire situation, given the existing sliding and separation between the steel tube and the concrete core produced by their different thermal expansion coefficients, the confinement of the concrete is not taken into account in the mechanical analysis. Subsequently, the increase of concrete compressive strength caused by this phenomenon is neglected in the post-heating phase, a conservative assumption.

\section{MODEL VALIDATION}

Given the unavailability of test data involving heating, cooling and post-heating stage under sustained load, the fibre model has been validated separately against tests at different stages, including experiments on CFST columns at room temperature [23] exposed to high temperatures [24]-[26] and after heating [5]. Such an approach has also been adopted by other authors $[8][9]$.

\subsection{Room temperature tests}

The model results are validated against experiments at room temperature. The detailed description of the reference tests, for both normal and high strength concrete infill, are given in [23] where a series of tests on CFST columns to investigate the effect of slenderness, diameter to thickness ratio, strength of concrete, and eccentricity on their behaviour is reported. The columns lengths were $2135 \mathrm{~mm}$ or $3135 \mathrm{~mm}$, and sections with different diameters were tested. The predicted load versus deflection responses at the mid-height of the columns is given in Fig. 3, with the experimental results for two of the slender specimens shown. There is reasonable agreement between calculated and measured values. 


\subsection{Fire response tests}

The fire behaviour of concentrically loaded CFST columns is simulated with reasonable accuracy by the model for different type of infills of both normal and high strength concrete. A sequentially coupled thermal-stress analysis is accomplished. This consists of two steps: (1) a sectional thermal analysis to compute the temperatures of the member and (2) a mechanical analysis. The heating regime curve is applied to the exposed surface along the entire length of the column. In this case, the sliding and separation between the two components produced by their different thermal expansion coefficients is taken into account.

Validation was undertaken using fire tests carried out by selected authors of the current paper (Romero et al. [24]) and also with results from circular columns tested by other researchers [25][26]. As an example, for three of the slender columns analysed, the comparison of the fire response in terms of axial displacement-time is shown in Fig. 4. The fibre model again shows reasonable agreement with the experiments for the two parameters compared; i.e. the fire resistance rating and maximum axial displacement.

When evaluating the overall response of the columns, the model produces a realistic response and shows reasonable accuracy when the axial displacement versus time curves are compared against experiments. The description of these specimens and additional validation is given in [12].

\subsection{Tests on residual strength of specimens heated without initial load}

The third step is the validation of the model against experiments on the residual strength of CFST columns heated without initial load. As detailed above, most of the works reviewed investigate stub columns with $L / D$ values about $1.9-3$, but in the tests carried out by some of the authors of the current paper (Rush et al. [5]), more slender specimens with a $L / D$ of 10 and 
a length of $1400 \mathrm{~mm}$ were tested. Further tests are required to provide additional experimental data for slender CFST columns.

Therefore, four circular CFST columns from the above study were used in the validation and in the subsequent analysis which is based on their geometries. Table 1 summarises the details of the columns. All of these were filled with concrete of nominal compressive strength $f_{c}=70 \mathrm{MPa}$ and the steel tubes had a yield strength of $f_{y}=355 \mathrm{MPa}$.

The specimens were heated in a ceramic lined standard furnace for 120 minutes following the ISO 834 fire curve [2] and cooled down for at least 120 minutes in the furnace, recording the temperatures. All the heating process was carried out under unloaded conditions. In Fig. 5 the predicted and measured temperatures are plotted showing reasonable agreement. For the thermal simulation, recommendations given in [6] and [12] are adopted. The inertia existing in the concrete core is observed in the delay (of about 15 minutes) of the temperature curve, where the concrete temperature increases even after the furnace has started to cool.

Finally, the specimens were tested as pinned-pinned up to failure. For each specimen, the load-deflection curve was registered during the test and the value of the residual strength $\left(N_{\text {post}}\right)$ was extracted. Table 1 contains the experimental and predicted residual strength values. The observed failure mode was global buckling and, in some cases, local buckling was observed which was subsequently determined to be a result of mild honeycombing of the concrete within the column.

In Fig. 6 a comparison between the experimental and the calculated curves is presented. With a mean error of 1.03 on the safe side the prediction of the load-deflection in the postheating stage is reasonable, despite the fact that the initial stiffness is not fully captured. 


\section{ANALYSIS OF THE POST-HEATING RESPONSE OF CFST COLUMNS UNDER SUSTAINED LOAD}

\subsection{Analysis procedure}

The complete analysis comprises the three stages: heating, cooling and post-heating under sustained load. This is shown schematically in Fig. 7.

First, an initial load $\left(N_{0}\right)$, which is a percentage of the ultimate capacity at ambient temperature, is applied simultaneously with the beginning of the heating stage and kept constant (Fig. 7a). The heating lasts until time th (Fig. 7b), and, at this moment, the fire temperature starts to decrease. Due to the thermal inertia of the concrete, the descent of the concrete cross-sectional temperatures is delayed (Fig. 7b).

The cooling stage continues until all the fibres in the section have reached ambient temperature $T_{0}$ at time $t_{c}$ (Fig. $7 \mathrm{~b}$ ). During these two stages the external applied load is maintained constant and equal to $N_{0}$ (Fig. 7a). However, once the post-heating stage is reached, the load is increased by small increments until failure (Fig. 7a and Fig. 7c).

In this model, the standard ISO 834 [2] fire curve is applied for heating and cooling stages to the exposed surface of the column along its whole length and therefore a descending branch is considered according to EN 1991-1-2 [16].

Ascending branch:

$T_{\mathrm{f}}=T_{0}+345 \log _{10}(8 t+1)$

Descending branch

$$
T_{\mathrm{f}}=\left\{\begin{array}{cc}
T_{h}-10.417\left(t-t_{h}\right) & \left(t_{h} \leq 30\right) \\
T_{h}-4.167\left(3-\frac{t_{h}}{60}\right)\left(t-t_{h}\right) & \left(30<t_{h}<120\right) \\
T_{h}-4.167\left(t-t_{h}\right) & \left(t_{h} \geq 120\right)
\end{array}\right.
$$


where $T_{f}$ is the fire temperature in ${ }^{\circ} \mathrm{C}\left(T_{f} \geq 20\right) ; T_{h}$ is the maximum temperature achieved in the heating stage in ${ }^{\circ} \mathrm{C}$; $t_{h}$ is the duration of the heating stage in minutes; and $t$, in this case, is the fire exposure time in minutes.

\subsection{Influence of load and heating time on the residual capacity}

Based on the model results, the influence of different parameters on the post-heating response of CFST columns under sustained load has been analysed. This was accomplished by taking as reference the characteristics of the specimens from Rush et al. [5] and used for validation in the previous section, since their capacity at room temperature was known (see Table 1). Most of the existing research focuses on stub columns $(L / D=1.9-3)$ whereas the columns studied here are more slender with a $L / D$ of 10 , which may produce a different response. The parameters studied were the load ratio $\left(m=N_{o} / N_{a m b i e n t}\right)$ and the heating time $\left(t_{h}\right)$. In addition, given that the specimens have the same outer diameter but tubes with different wall thickness $(t)$, the effects resulting from this could also be observed.

Each case is identified by its heating time and load ratio. In this investigation, standard fire resistance times (i.e. R15, R30...) were adopted as heating times, since these are the actual values used in the practice. Since the objective of the current work is to study the response post-heating, the heating times were chosen to assure that all columns went through all the stages of the analysis and avoided their failure during heating or cooling. To achieve this, the fire resistance rating (FRR) of each column for different load ratios needed to be determined.

As preliminary work for the parametric analysis the FRR of each column under different loads was calculated. In this case, the lowest FRR for a load ratio of $m=0.2$ was 39 minutes and, consequently, that was the limiting time. Therefore, this was the FRR used as reference to set the values of the heating times $\left(t_{h}\right)$ for the parametric analysis. According to 
this value, the values of $t_{h}$ that can be considered to assure the complete analysis were 15 minutes and 30 minutes, respectively, as shown in Table 2.

In total, 24 cases were analysed and the response during all stages was noted. Although the range of variation of the load ratio was narrow, this was explicitly established to avoid failure of the columns during heating and cooling stages. According to the limiting fire response predicted for this group of columns, higher values of $m$ or $t_{h}$ would have caused the premature failure of the column. As noted above, further studies in this area are required.

The different stages of the response of the columns in terms of the load versus axial displacement curves at the tops of the columns are given in Fig. 8. The initial loading (Stage $\mathrm{AB})$ determines the position of the horizontal plateau on the y-axis according to the value of the sustained load during heating and cooling. When the column expands during heating (Stage BC), the horizontal plateau grows to the positive side up to a maximum. The column then contracts due either to the yielding of the steel tube during heating or to the start of the cooling phase (Stage CD). Therefore, the axial displacement becomes smaller and the column returns to its initial position and starts to shorten, having a negative axial displacement. At the end of the cooling (Point D), a permanent contraction of the column can be observed and, finally, the displacement increases linearly with the gradual increment of load up to failure (Stage DE).

Fig. 9 shows the load-axial displacement curves resulting from all of the cases analysed. For each column series, the specifications of the simulation are in the legend of the graphs: the type of line pattern identifies the load ratio, and the colour, black or grey, the heating time. In this case, the positive side of the $\mathrm{x}$-axis means expansion and the negative side, contraction.

It can be seen in Fig. 9 that the permanent deformation increases considerably with an increase in the heating time and in the load ratio and it is inherently linked to the yielding of the steel tube during the heating phase, when it is the component which supports $100 \%$ of the 
load. Attending to this phenomenon, two different response paths are predicted by the model as shown in Fig. 10 for the two specimens with $m=0.10$ from Series C2. The graphs describe the axial displacement evolution of the top of the column with time.

In Fig. 10a the column was heated for $t_{h}=15$ minutes and in Fig. $10 \mathrm{~b}$ for $t_{h}=30$ minutes. Both cases show the typical behaviour at the first stages of heating for a CFST column. The steel tube expands faster than the concrete core due to its higher thermal expansion coefficient and its direct exposure. As a result, the axial displacement rate of both components is uncoupled, and the entire applied load is supported by the steel tube alone. In Fig. 10a, the heating phase is short, and the cooling starts before the steel tube reaches its yielding point. The contraction of the steel tube is coincident with its cooling, recovering back to its initial position in line with the concrete core and working together from this point on. It can be seen in Fig. 10a that, at the beginning of the post-heating phase, the permanent contraction is very low.

However, for a longer heating time $t_{h}=30$ minutes in Fig. $10 \mathrm{~b}$, the yielding of the steel section occurs, and the steel tube starts to shorten before the cooling has begun. After cooling, the thermal expansion of the steel tube is recovered, and the tube becomes shorter reaching the position of the concrete core that is still expanding slowly since the temperatures in its cross-section are increasing given concrete's lower thermal inertia. Thus, because of the plastic strain sustained by the steel during heating, the steel tube seeks to contract to below the level of the concrete. As a result, during cooling in contrast to the response discussed in Fig. 10a, the concrete core works to support most of the load.

This continues until the applied load is increased, resulting compression strains in the concrete. When the strain in the concrete matches the plastic strain sustained by the steel during the heating phase (i.e. the top of the concrete is level with the top of the steel), both components again work together as a composite section. Contrary to Fig. 10a, in Fig. 10b the 
permanent contraction of the steel at the start of the post-heating is considerable - in this case almost 10 times that shown in Fig. 10a.

In Fig. 11 and Fig. 12, the axial displacement-time response is shown for the 24 cases analysed for $t_{h}=15$ minutes and $t_{h}=30$ minutes respectively. From these graphs it can be seen that there is a high influence of the load ratio on the permanent contraction of the steel after cooling, particularly for the cases with $t_{h}=30$ minutes and thinner steel tubes.

Referring to Fig. 9, another aspect that can be noted is that the highest ultimate loads are achieved by the specimens of Series C1 (Fig. 9a) with thicker steel tube wall and for the lowest heating time, as expected, since the contribution of the steel, which fully recovers during cooling, is higher (steel ratio 36\%). The ultimate load at post-heating decreases notably with the increase of the heating time but the effect of the load ratio is not as obvious. For $t_{h}=30$ minutes it is more notable than the higher the initial load, the smaller the ultimate capacity at post-heating, although the variation is comparatively small.

On the contrary, for $t_{h}=15$ minutes the effect of the load ratio increment is small, particularly for the specimen with thicker steel tube. For the series with thinner wall however, the ultimate load tends to increase slightly with the load ratio. Again, this phenomenon could be explained according to the two typical responses that the model provides for the columns (discussed in Fig. 10) and the force distribution associated with each one. As an example, in Fig. 13, the force distribution between the two components in time is plotted for Series C3 specimens with $t_{h}=15$ minutes. In Fig. 13 a the column was loaded with $m=0.10$, whereas in Fig. $13 \mathrm{~b}$ the load ratio was $m=0.20$. As with Fig. 10, the inclusion of the graphs in Fig. 13 aims to better highlight the mechanisms of response of CFST columns exposed to the full load-temperature-time regime. The main difference lies once more in the occurrence of yielding in the steel tube. In the case of the two columns of Fig. 10, the increase in the heating time caused the yielding of the steel prior to the cooling. In Fig. 13, where the specimens have 
a thinner steel tube wall, it is the increment in the load ratio which produces this effect, since the degradation of the material is important even for mild heating times.

In Fig. 13a, the expanded steel tube does not yield during the first stages of heating and it is the steel tube which supports the majority of the load until it cools down and starts sharing the load with the concrete core. At the end of the cooling, the steel tube is supporting $73 \%$ of the load. Once the post-heating starts i.e. the load is increased, the load borne by each component increases until the steel tube starts to yield, increasing the deflection of the column ( $m=0.10$, Fig. 14c). At this point, the concrete contribution growths quickly but its role is limited, since with the rapid increment of deflection the column fails.

On the other hand, in Fig. 13b, as the steel yields during the heating phase of the analysis, the steel contracts to below the level of the concrete during cooling. Thus, at the first stages of the cooling, the force distribution undergoes an inversion since the load sustained by the steel tube is gradually transferred to the concrete core as the column shortens. The concrete core is thus the element bearing the majority of the load, but the material at the inner layers is degrading since, due to the thermal cross-sectional inertia, the temperature there is still increasing. This combination of loading and temperature in the concrete core makes the deflection growth gradually after a small recovery $(m=0.20$, Fig. $14 \mathrm{c})$. At the end of cooling deflection is stabilized. With the increment of axial compression post-heating, the load supported by each component increases. The steel tube, which has completely recovered its strength and stiffness, controls the response. The concrete core contribution in this case is higher during all phases since it had to deal with the yielding of the steel tube and now is still able to contribute to a reasonable extent given that during most of the post-heating is entirely working under compression, thus increasing its efficiency.

The results in terms of deflection at mid-height versus time for the 24 cases are summarised in Fig. 14 and Fig. 15. Generally, both the deflection at heating and at the start of 
the post-heating are, as expected, higher for those specimens with higher heating times, and both increase with the load ratio. Especially for the cases with $t_{h}=15$ minutes, the deflection has low values until the end of the post-heating, when the column losses its stability.

When the heating time is $t_{h}=30$ minutes, Fig. 15 , the force distribution pattern is generally that shown in Fig. 13b. In these curves the different stages of the response can also be identified. For example, taking as a reference $m=0.20$ from Fig. $15 \mathrm{a}$, it can be seen that during heating, deflection at mid-height increases. Given the non-uniform thermal expansion induced in the cross-section with increasing temperature, redistribution of stresses takes place to maintain the planarity of the sections. As a consequence, the column deforms and deflects. On the contrary, when the cooling stage starts, the column recovers to some extent. Nevertheless, the deflection grows gradually due to the load and temperature acting in the inner part of the concrete core and becomes more stable at the end of cooling. At post-heating, the deflection increases due to the load increase until final failure of the column.

Finally, the effect of the load ratio and heating time was quantified by means of the residual capacity index, given by Eq. 2 :

$\boldsymbol{r}=\frac{N_{\text {post }}}{N_{\text {ambient }}}$

The index values are presented in Fig. 16 for all the cases studied. For those specimens heated during $t_{h}=15$ minutes, the residual index is about 0.8 , independent of the steel ratio. That changes for $t_{h}=30$ minutes, where a variation of the average values of $r$ is visible with a decrease in the steel tube thickness, ranging from 0.76 to 0.62 . As previously noted, for the same load ratio an increment in the heating time results in a decrement of the post-heating capacity, and this is more notable for thinner steel tubes. This average decrement is $6 \%$ for Series $\mathrm{C} 1$ and goes up to $20 \%$ for the series with the thinnest steel tube.

The loss of strength with an increment in the load ratio is relatively small and, as already noted, in some cases is slightly higher. This effect was also observed by Song et al. [9] using 
their model for CFST columns under combined temperature and loading. In any case, additional studies covering a wider range of slenderness and load ratios would be necessary to completely understand and model the influence of sustained load.

\section{SUMMARY AND CONCLUSIONS}

In this work a fibre beam model for the post-heating response of CFST columns is presented. The model considers realistic features and is able to reproduce the response of an axially loaded CFST column during three stages, namely: heating, cooling, and post-fire. According to the results obtained using this model, the following conclusions can be drawn:

- The proposed fibre model can be used to simulate the response of CFST columns for the full fire exposure process (i.e. heating and cooling) under sustained load. The model was validated for each stage separately, given the unavailability of detailed experiments on slender CFST columns for all phases. Although numerical models are an effective alternative to conduct studies, more experimental tests are needed to investigate the postheating behaviour of such columns.

- Based on the simulations, two different responses were identified according to the behaviour of the column during the initial stages of heating, given by the combined load ratio and heating time. The predictions of the model show that the sustained load during heating leads to a permanent contraction of the column. The value of this deformation depends significantly on the heating time. Particularly for the specimens with low steel ratio the influence of the load ratio is also important for low heating times due to the yielding of the steel tube. In this case, the permanent plastic deformation for a load ratio $m=0.20$ is 23 times that for $m=0.10$.

- The validated model was used to perform a parametric analysis to study the influence of the load ratio and the heating time on the post-heating response of the columns, 
accounting for the combined effects of loading and heating. The ultimate capacity of the columns at post-heating is more sensitive to an increment in the heating time than in the initial load. This was also corroborated by the analysis of the residual capacity index.

It must be noted that the model presented in this paper corresponds to an isolated column with free elongation. The behaviour of a column within a realistic structure differs from that of an isolated column, and this is even more important at elevated temperature where the increment in the column relative stiffness to the adjacent non-exposed structural members leads to changes not only in its structural boundary conditions but also to its timehistory of loading conditions. This issue requires additional research.

\section{ACKNOWLEDGEMENTS}

The authors gratefully acknowledge the financial support given by Universitat Jaume I (Spain) E-2018-18 and by Generalitat Valenciana (Spain) BEST/2017/141 for the first author's stays as a visiting fellow at the School of Engineering of the University of Edinburgh. The first author also would like to express her sincere gratitude to Prof Bisby and Dr Rush for their invitation to the University of Edinburgh. 


\section{REFERENCES}

[1] Han LH, Yang YF, Yang H, Huo J. Residual strength of concrete-filled RHS columns after exposure to the ISO-834 standard fire. Thin-Walled Structures 2002; 40: 991-1012.

[2] ISO (International Standards Organization). ISO 834: Fire resistance tests, elements of building construction. Switzerland: International Standards Organisation; 1980.

[3] Han LH, Huo J. Concrete-Filled Hollow Structural Steel Columns after Exposure to ISO834 Fire Standard. Journal of Structural Engineering 2003; 129 (1): 68-78.

[4] Huo J, Huang G, Xiao Y. Effects of sustained axial load and cooling phase on post-fire behavior of concrete-filled steel tubular stub columns. Journal of Constructional Steel Research 2009; 65: 1664-1676.

[5] Rush DI, Bisby LA, Jowsey A, Lane B. Residual capacity of fire-exposed concrete-filled steel hollow section columns. Engineering Structures 2015; 100: 550-563.

[6] Rush D, Bisby L, Gillie M, Jowsey A, Lane B. Furnace tests on unprotected and protected concrete filled structural hollow sections. Fire Safety Journal 2015; 78: 71-84.

[7] Tao Z, Ghannam M, Song T-Y, Han LH. Experimental and numerical investigation of concrete-filled stainless steel columns exposed to fire. Journal of Constructional Steel Research 2016; 118: 120-134.

[8] Yang H, Han LH, Wang YC. Effects of heating and loading histories on post-fire cooling behaviour of concrete-filled steel tubular columns. Journal of Constructional Steel Research 2008; 54: 556-570.

[9] Song T-Y, Han LH, Yu HX. Concrete filled steel tube stub columns under combined temperature and loading. Journal of Constructional Steel Research 2010; 66: 369-384.

[10] Yao Y, Hu XX. Cooling behavior and residual strength of post-fire concrete filled steel tubular columns. Journal of Constructional Steel Research 2015; 112: 282-292. 
[11] Filippou FC, Constantinides M. FEDEASLab. Getting Started Guide and Simulation Examples. Technical Report NEESgrid-2004-22, Berkeley, CA: Civil and Environmental Eng. Dept. University of California at Berkeley, 2004.

[12] Ibañez C, Romero ML, Hospitaler A. Fiber beam model for fire response simulation of axially loaded concrete filled tubular columns. Engineering Structures 2013; 56: 182193.

[13] Ibañez C, Aguado JV, Romero, ML, Espinos A, Hospitaler A. Fire design method for concrete filled tubular columns based on equivalent concrete core cross-section. Fire Safety Journal 2015; 78: 10-23.

[14] Ibañez C, Romero ML, Hospitaler A. Effects of axial and rotational restraints on concrete-filled tubular columns under fire. Journal of Constructional Steel Research 2016; 125: 114-127.

[15] Spacone E, Ciampi V, Filippou FC. Mixed formulation of nonlinear beam finite-element. Computers \& Structures 1996; 58 (1): 71-83.

[16] CEN. EN 1991-1-2, Eurocode 1: Actions on structures, Part 1.2: General actions Actions on structures exposed to fire. Brussels, Belgium: Comité Européen de Normalisation; 2002.

[17] CEN. EN 1993-1-2, Eurocode 3: Design of steel structures, Part 1.2: General rules Structural fire design. Brussels, Belgium: Comité Européen de Normalisation; 2005.

[18] Lie TT. Fire resistance of circular steel columns filled with bar-reinforced concrete. Journal of Structural Engineering- ASCE 1994; 120 (5): 1489-1509.

[19] Kodur VKR, Wang TC, Cheng FR. Predicting the fire resistance behavior of high strength concrete columns. Cement and Concrete Composites 2004; 26: 141-153. 
[20] CEN. EN 1992-1-2, Eurocode 2: design of concrete structures, Part 1.2: General rules structural fire design. Brussels, Belgium: Comité Européen de Normalisation; 2004.

[21] CEN. EN 1994-1-2, Eurocode 4: Design of composite steel and concrete structures, Part 1.2: General rules - Structural fire design. Brussels, Belgium: Comité Européen de Normalisation; 2005.

[22] Li YH, Franssen JM. Tests results and model for the residual compressive strength of concrete after a fire. Journal of Structural Fire Engineering 2011; 2(1): 29-44.

[23] Portolés JM, Romero ML, Bonet JL, Filippou FC. Experimental study of high strength concrete-filled circular tubular columns under eccentric loading. Journal of Constructional Steel Research 2011; 64 (4): 623-633.

[24] Romero ML, Moliner V, Espinos A, Ibañez C, Hospitaler A. Fire behavior of axially loaded slender high strength concrete-filled tubular columns. Journal of Constructional Steel Research, 2011; 67: 1953-1965.

[25] Lie TT, Chabot M. Experimental studies on the fire resistance of hollow steel columns filled with plain concrete. Internal report No. 611. Ottawa, Canada: Institute for Research in Construction, National Research Council of Canada (NRCC); 1992.

[26] Kim DK, Choi SM, Kim JH, Chung KS, Park SH. Experimental study on fire resistance of concrete-filled steel tube column under constant axial loads. Steel Structures 2005; 5: $305-313$. 


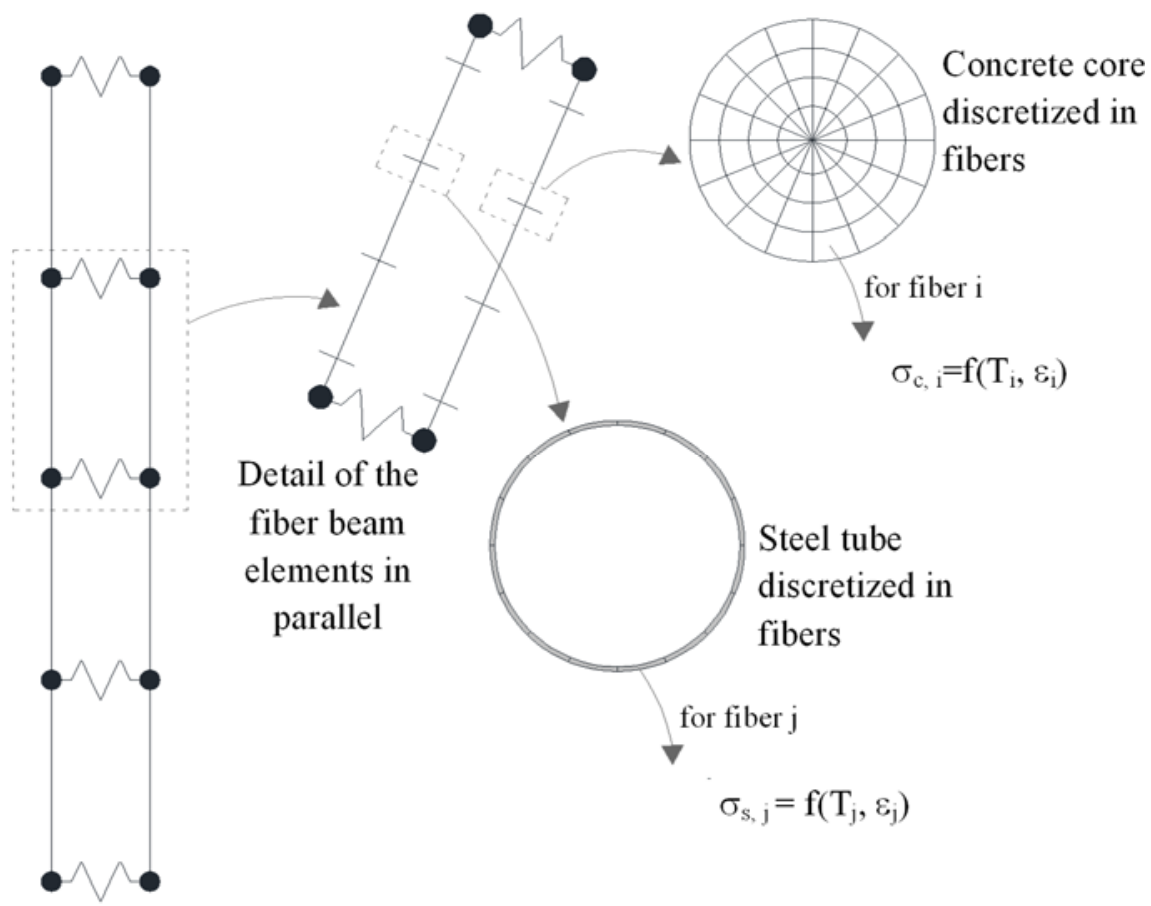

Fig. 1. Parallel model scheme and discretization of the section [12].

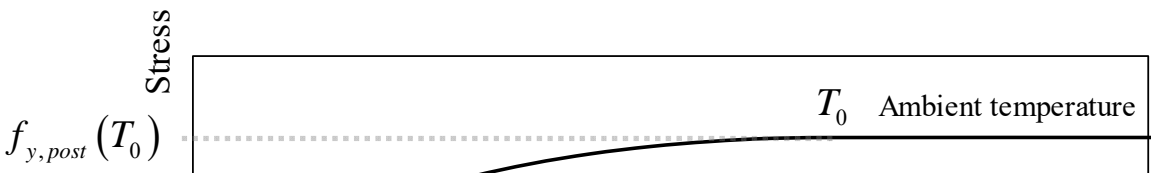


Fig. 2. Linear interpolation of yield strength of steel at cooling stage.

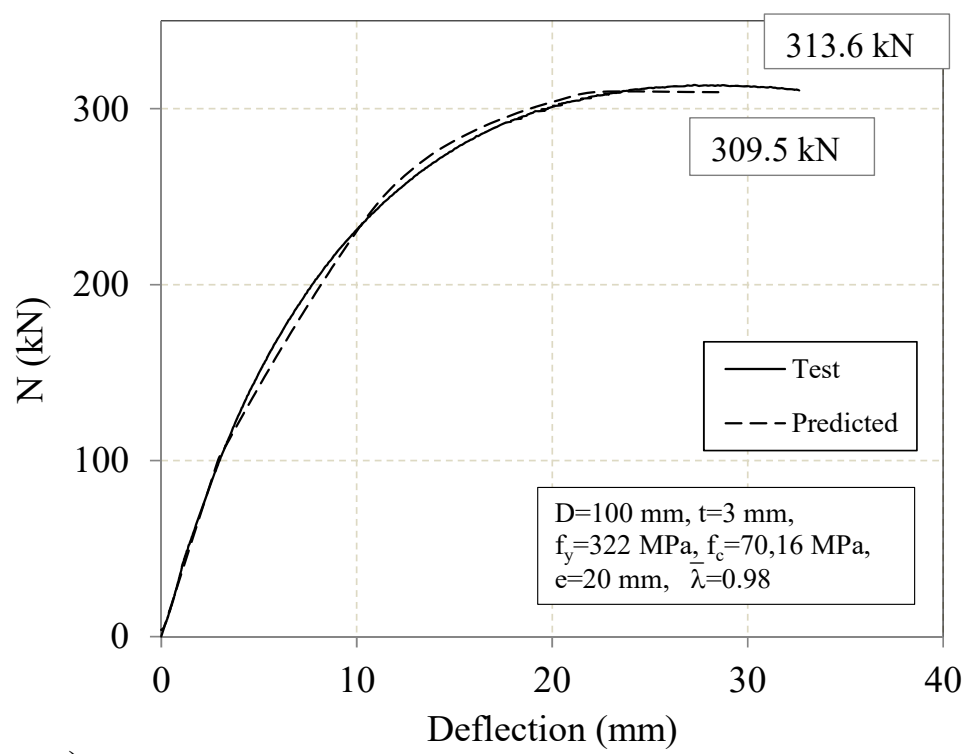

a)

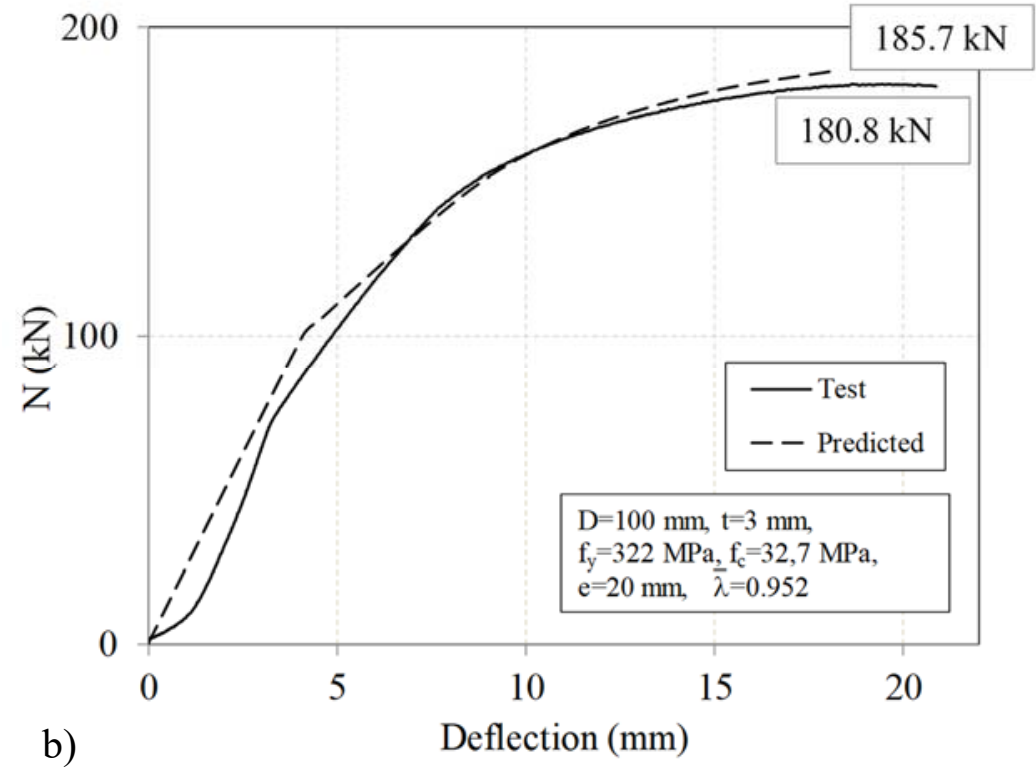

Fig. 3. Load-deflection curves at room temperature a) C100-5-2-60-20; b) C100-3-2-30-20 [23]. 

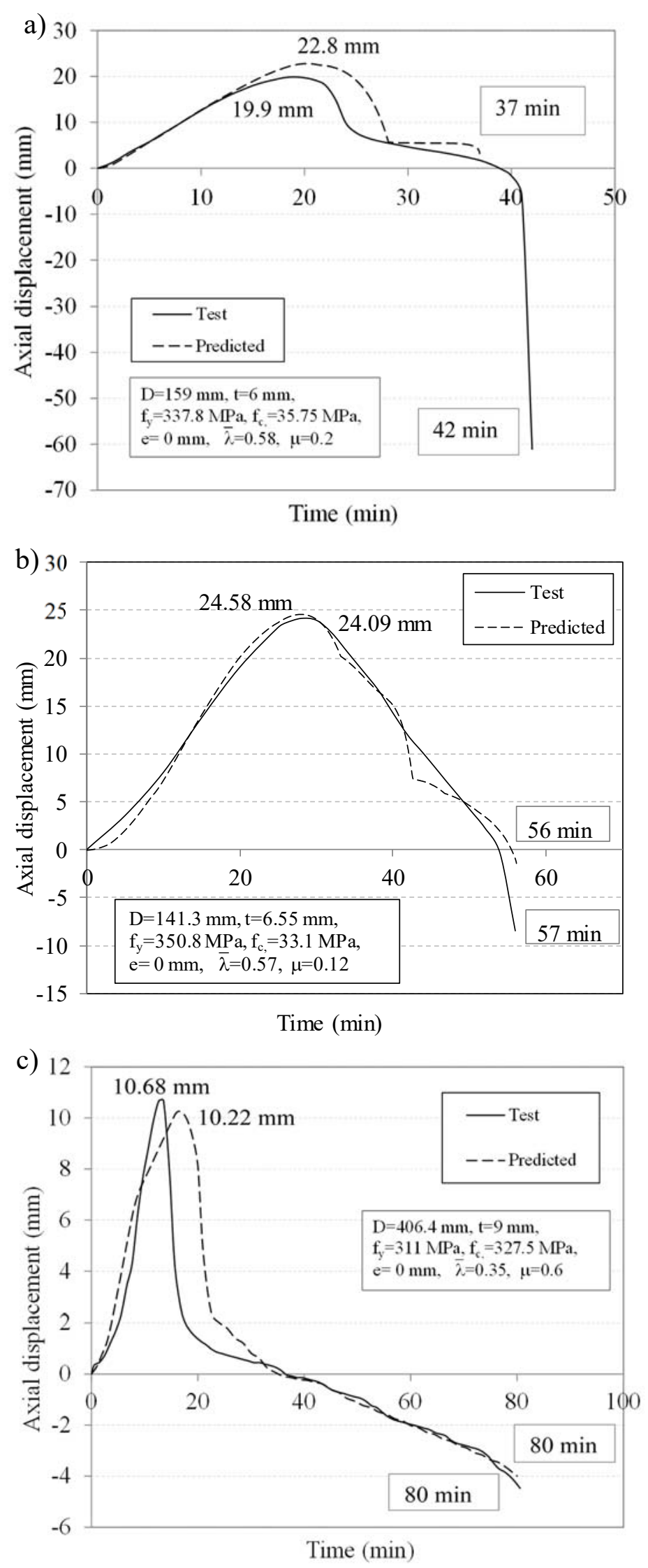

Fig. 4. Axial displacement - Time: a) C-159-6-3-30-0-20 [24]; b) C-04 [25]; c) CBL-1 [26]. 


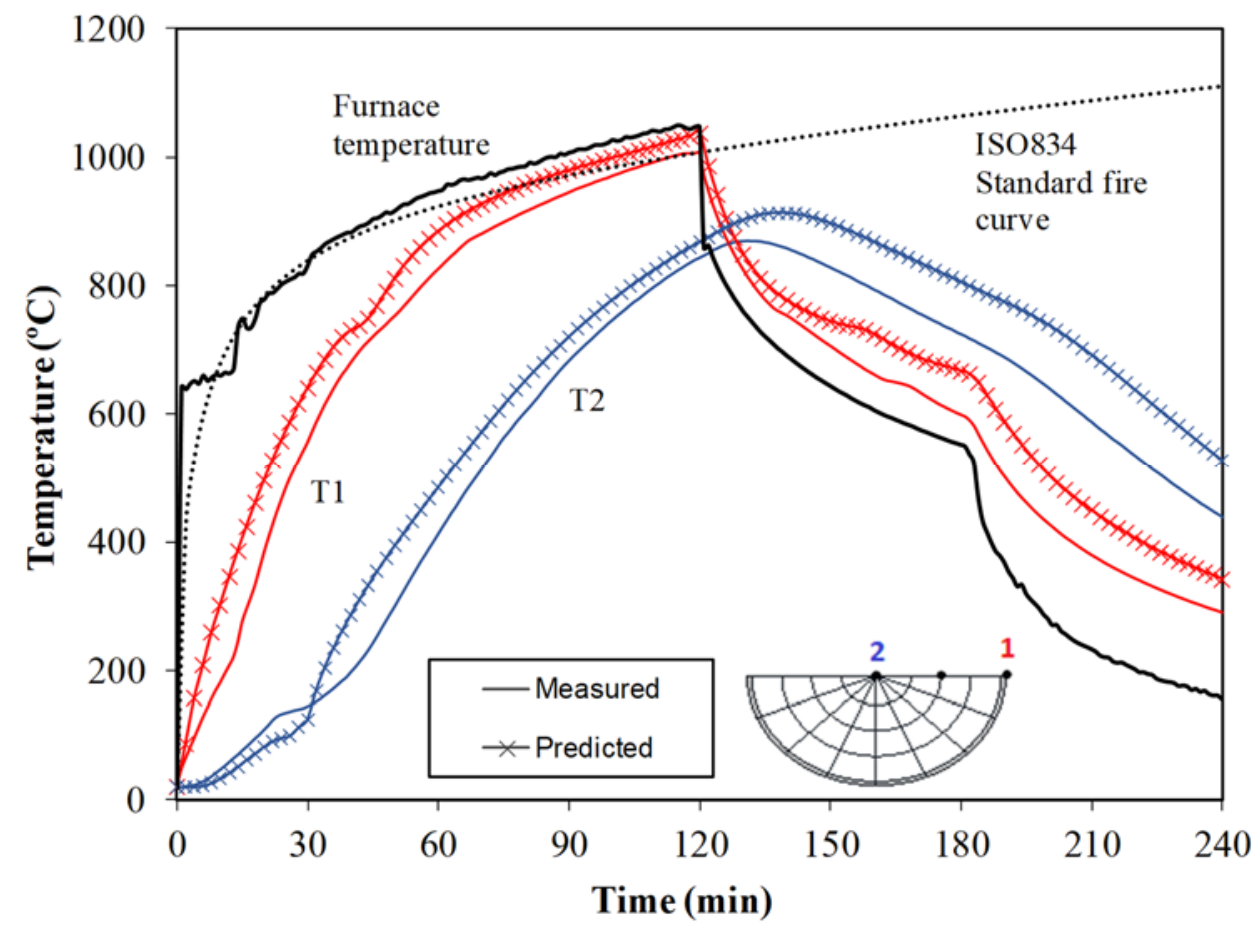

Fig. 5. Temperature-time for specimen $\mathrm{C} 1$. 

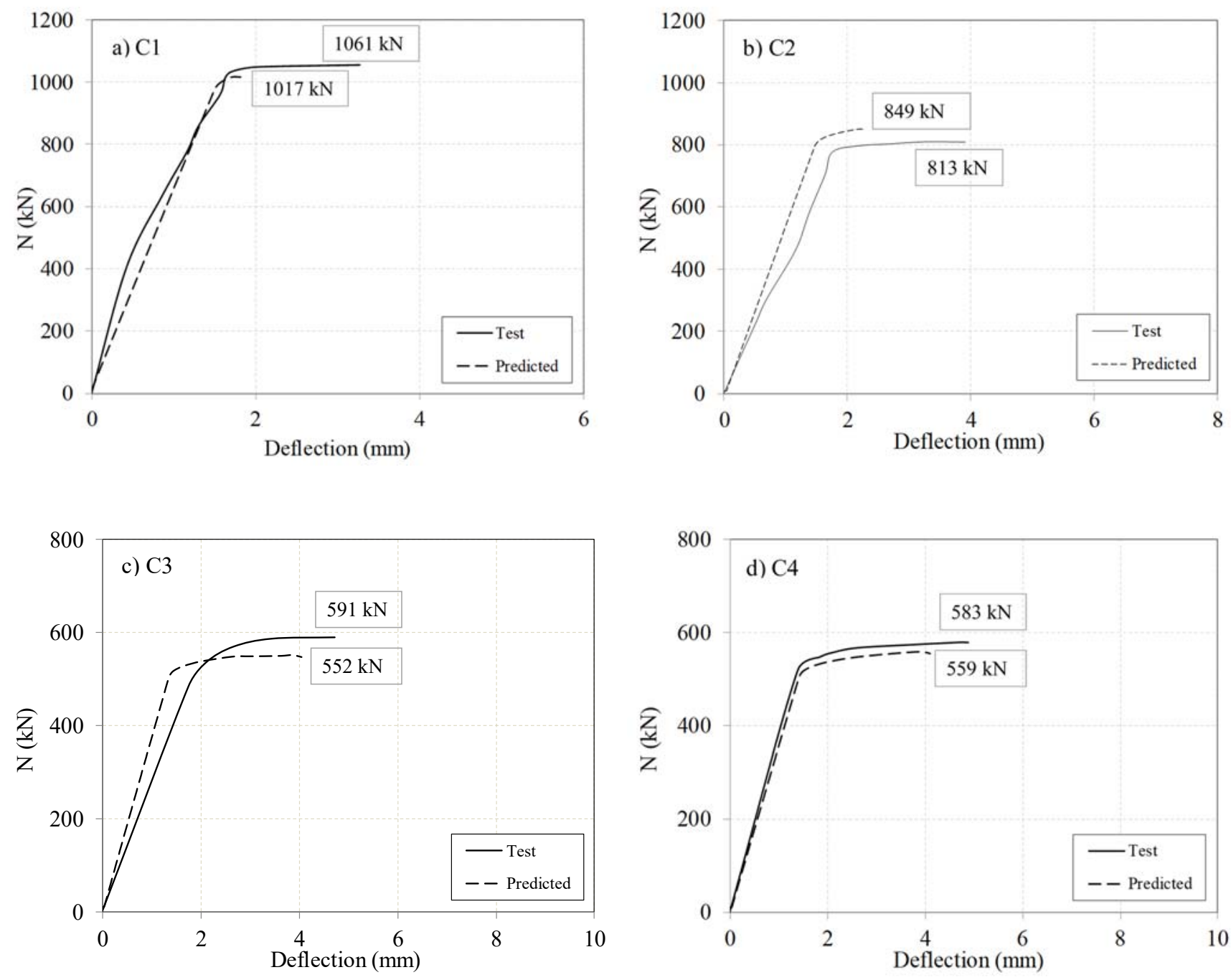

Fig. 6. Load-deflection curves at post-fire stage. 


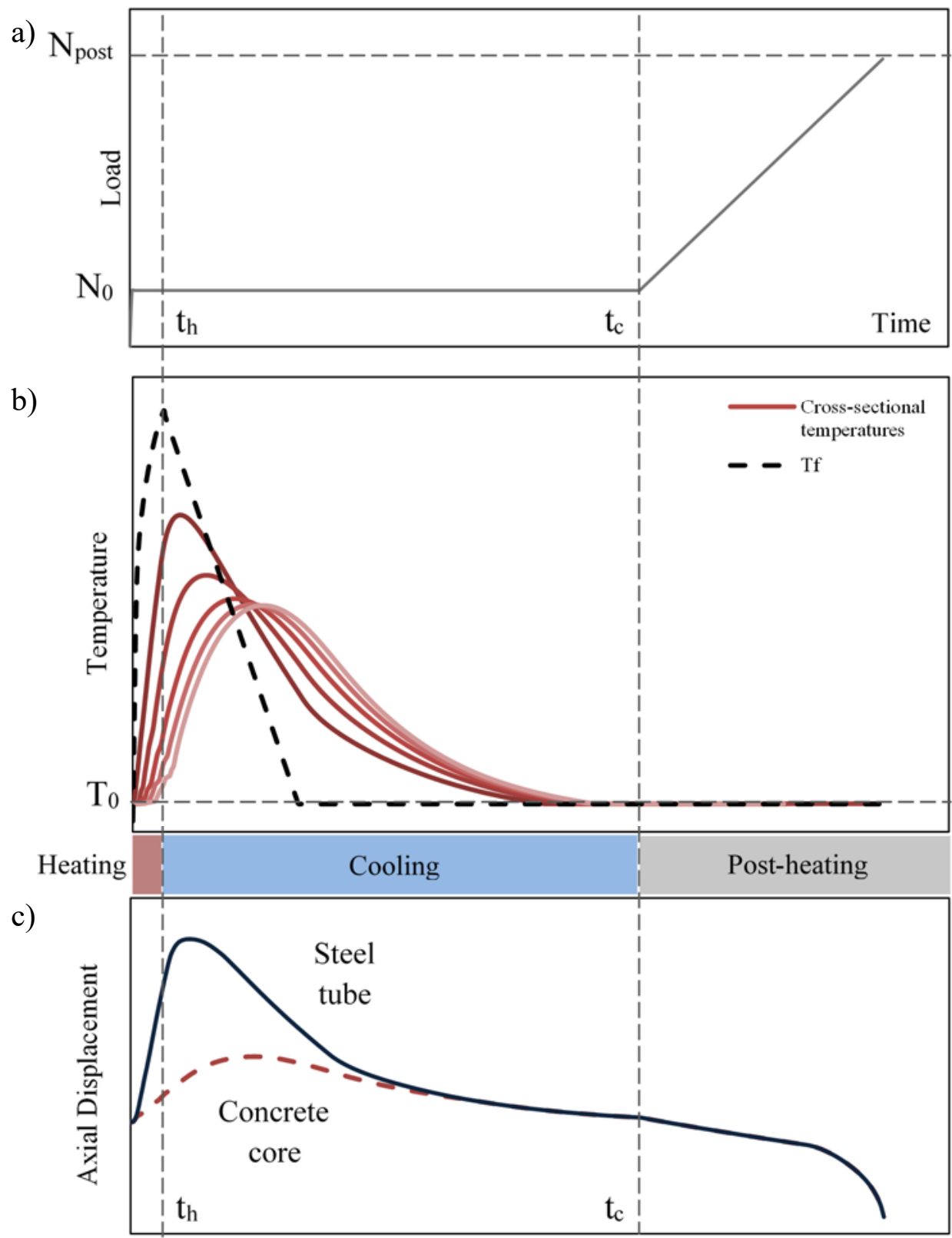

Fig. 7. Scheme of the analysis procedure. 


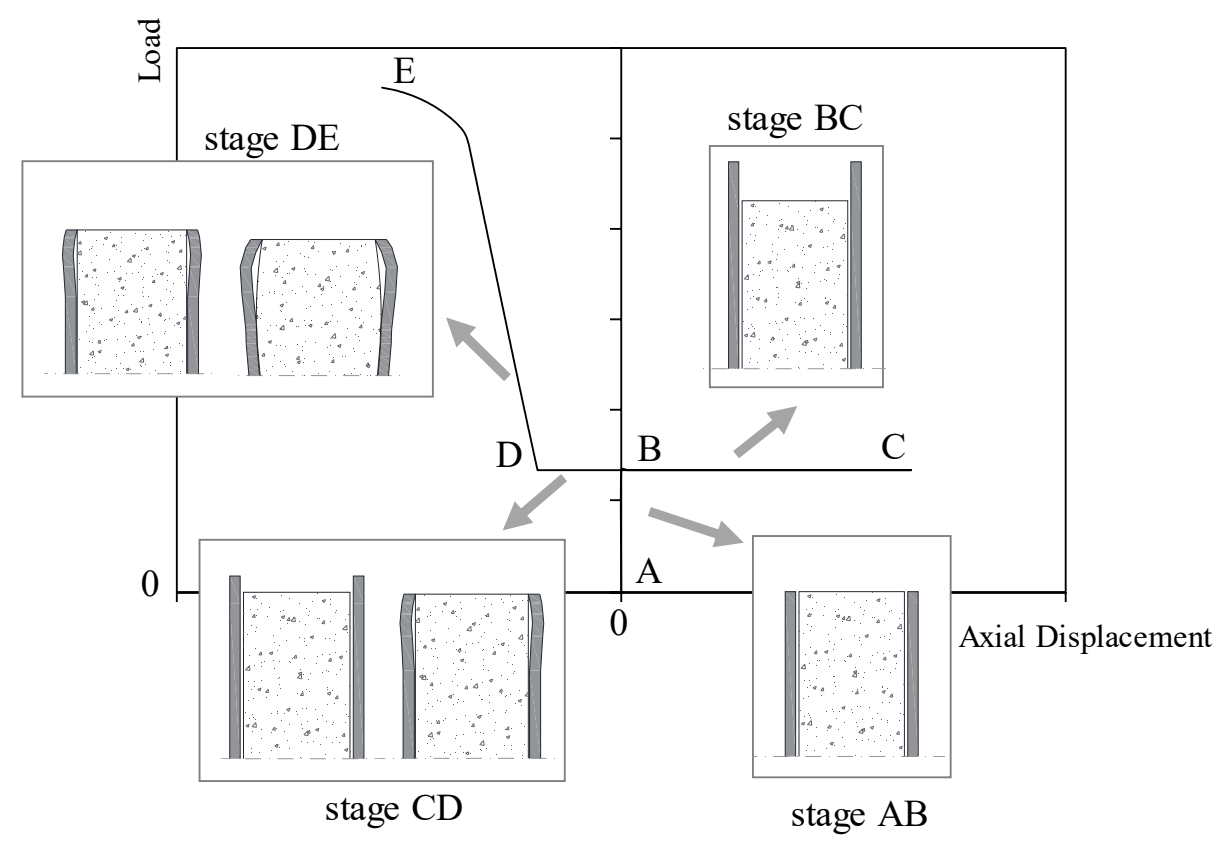

Fig. 8. Typical load-axial displacement curve.

a)
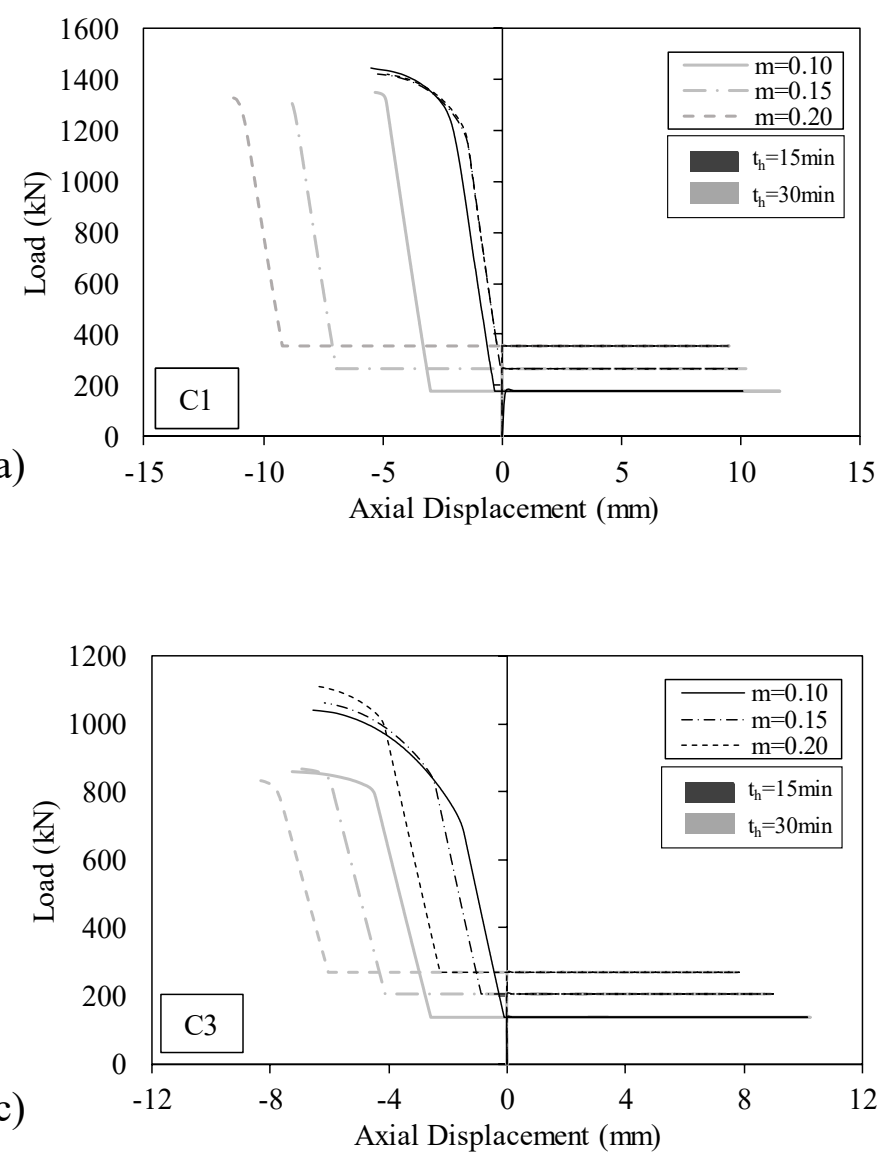

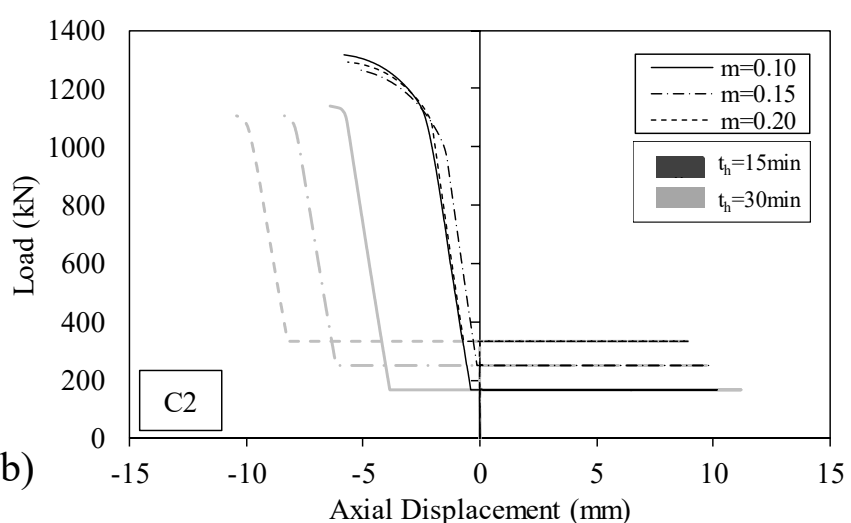

d)

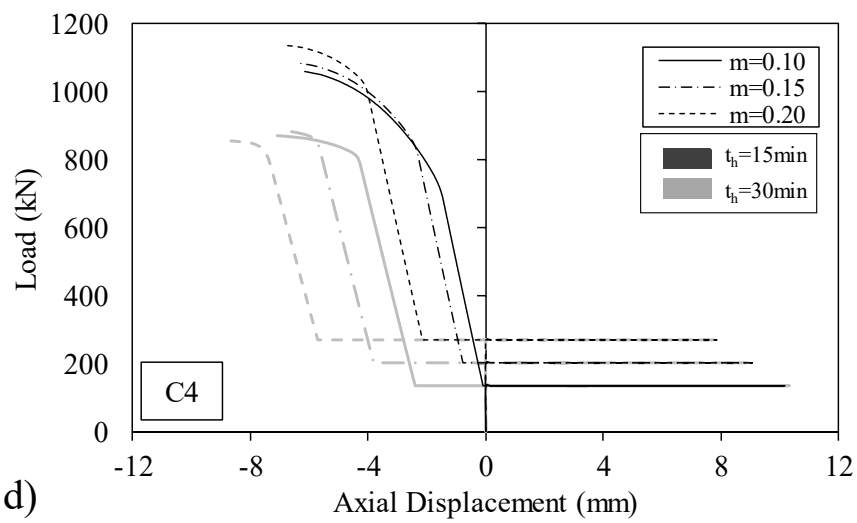

Fig. 9. Influence of load ratio and heating time on the load-axial displacement curves. 

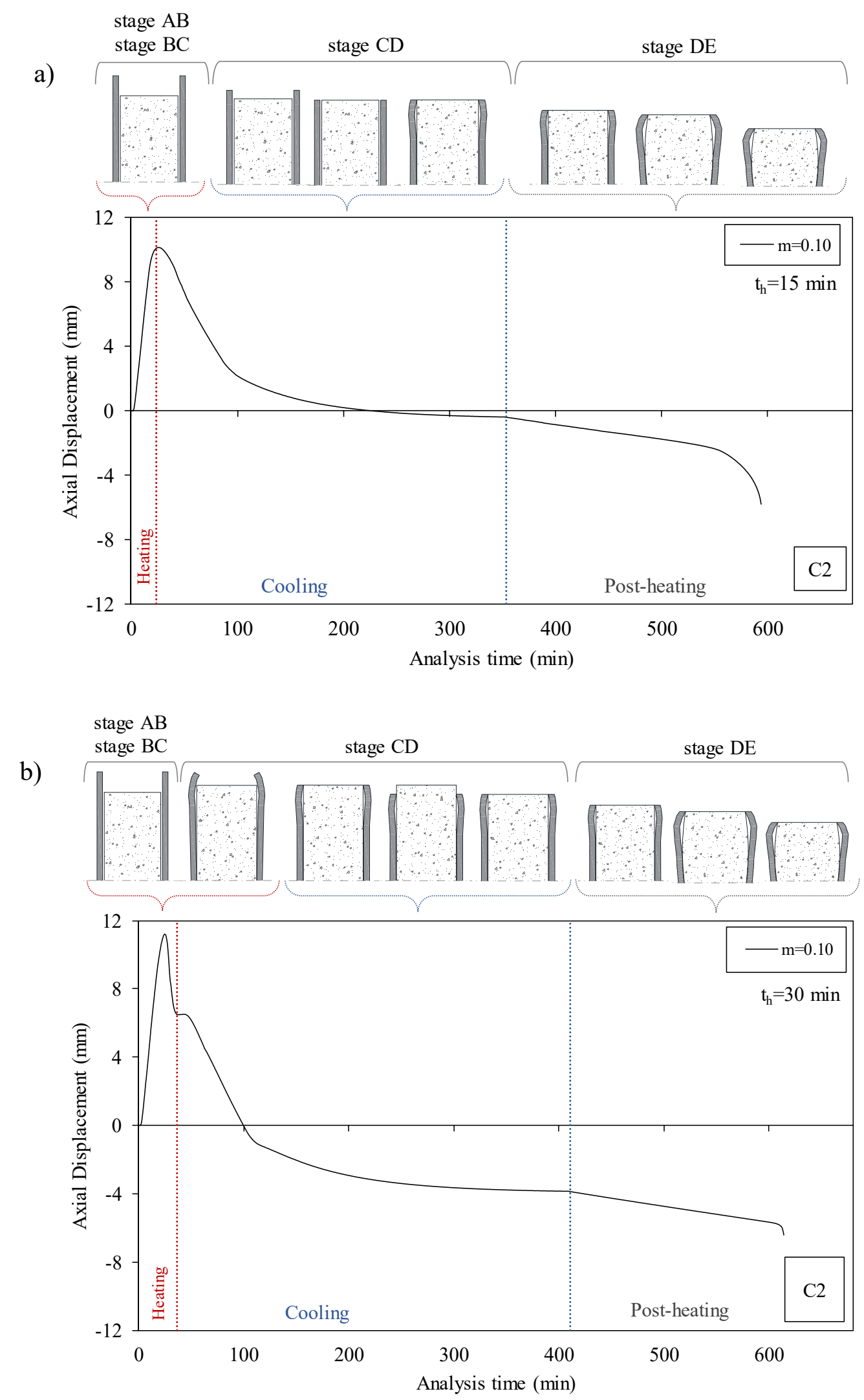

Fig. 10. Typical axial displacement -time curves under combined temperature and loading. 

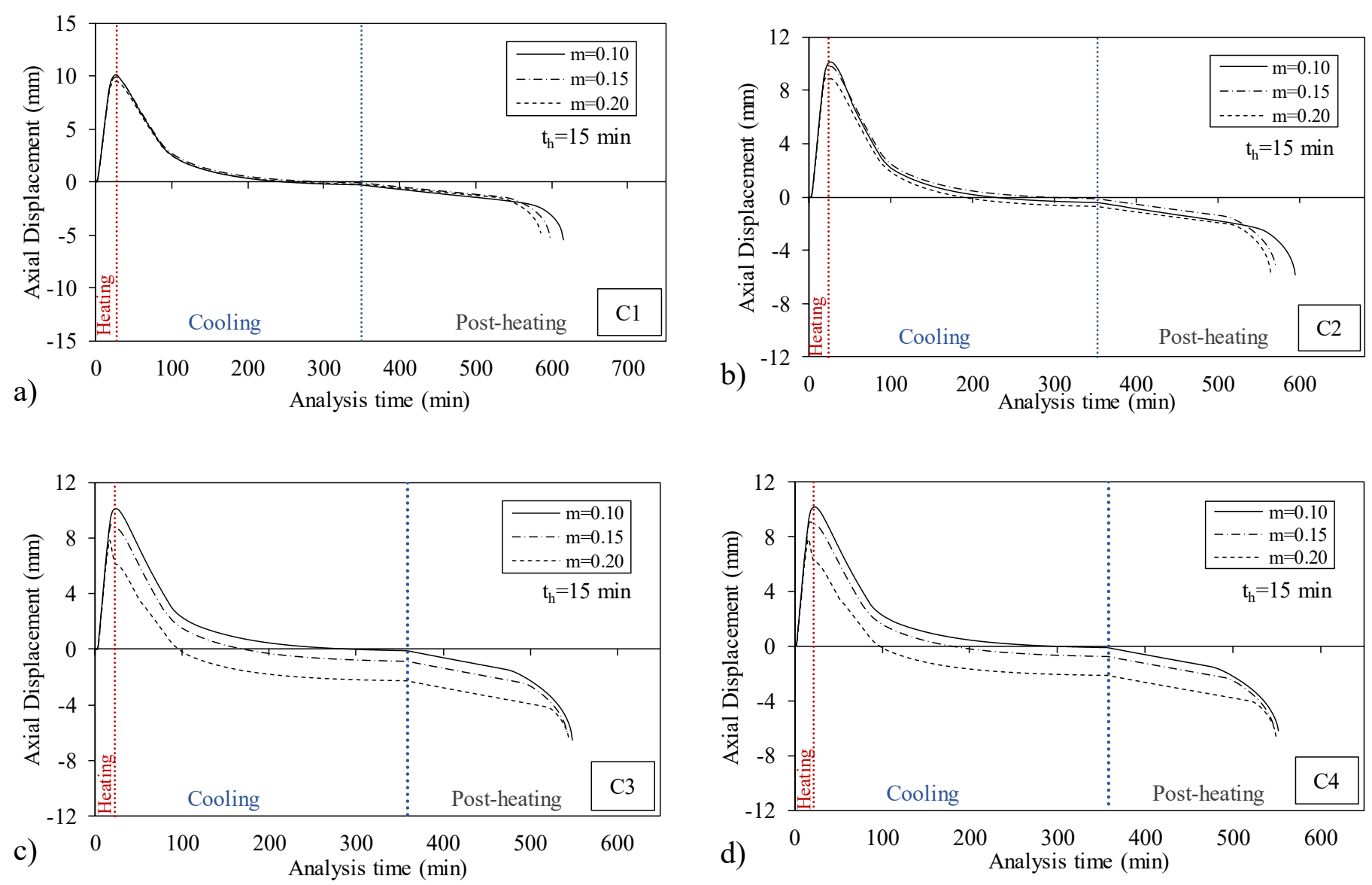

Fig. 11. Influence of load ratio on the axial displacement-time curves for $t_{h}=15$ minutes. 

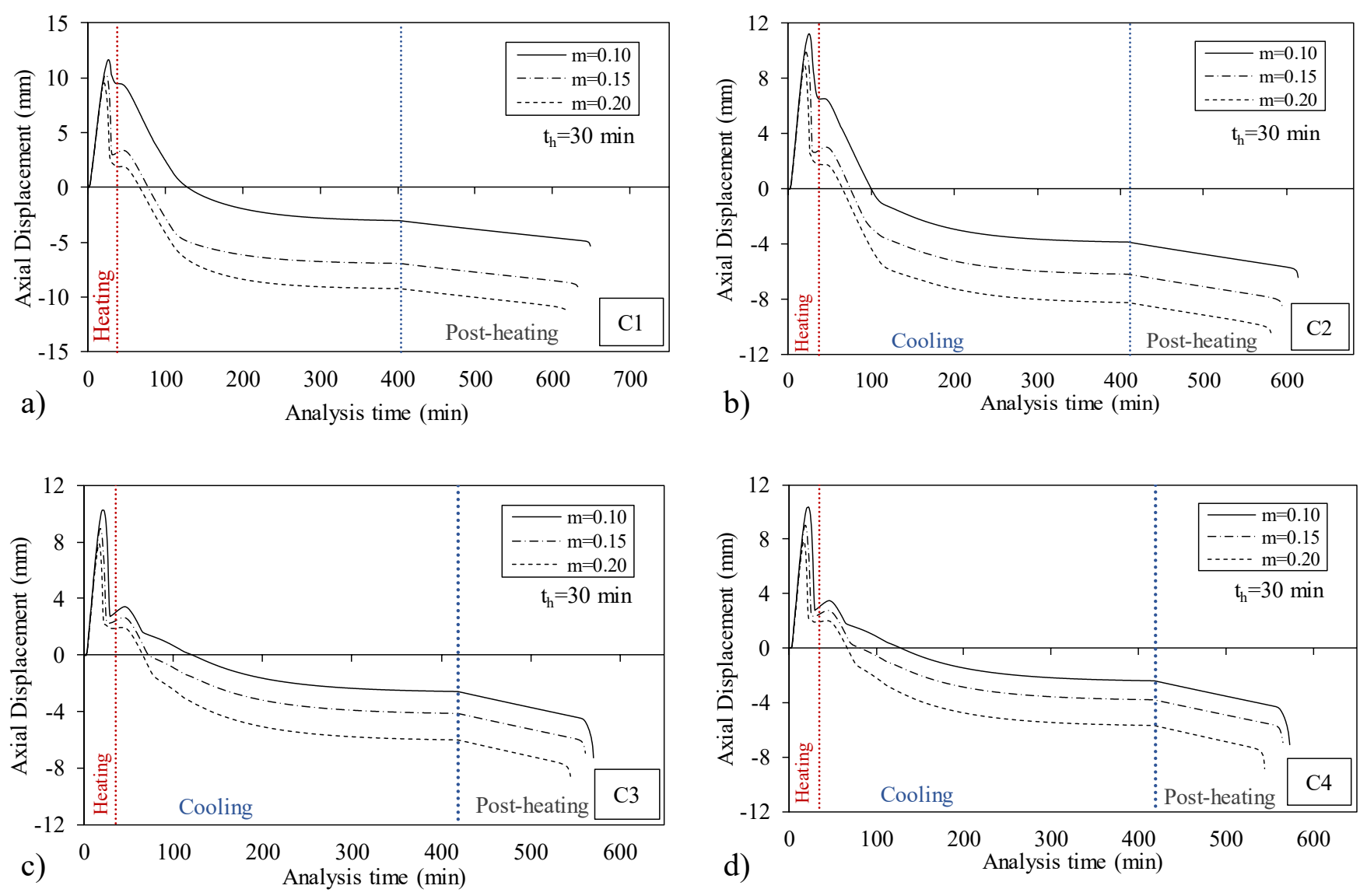

Fig. 12. Influence of load ratio on the axial displacement-time curves for $t_{h}=30$ minutes. 
a)

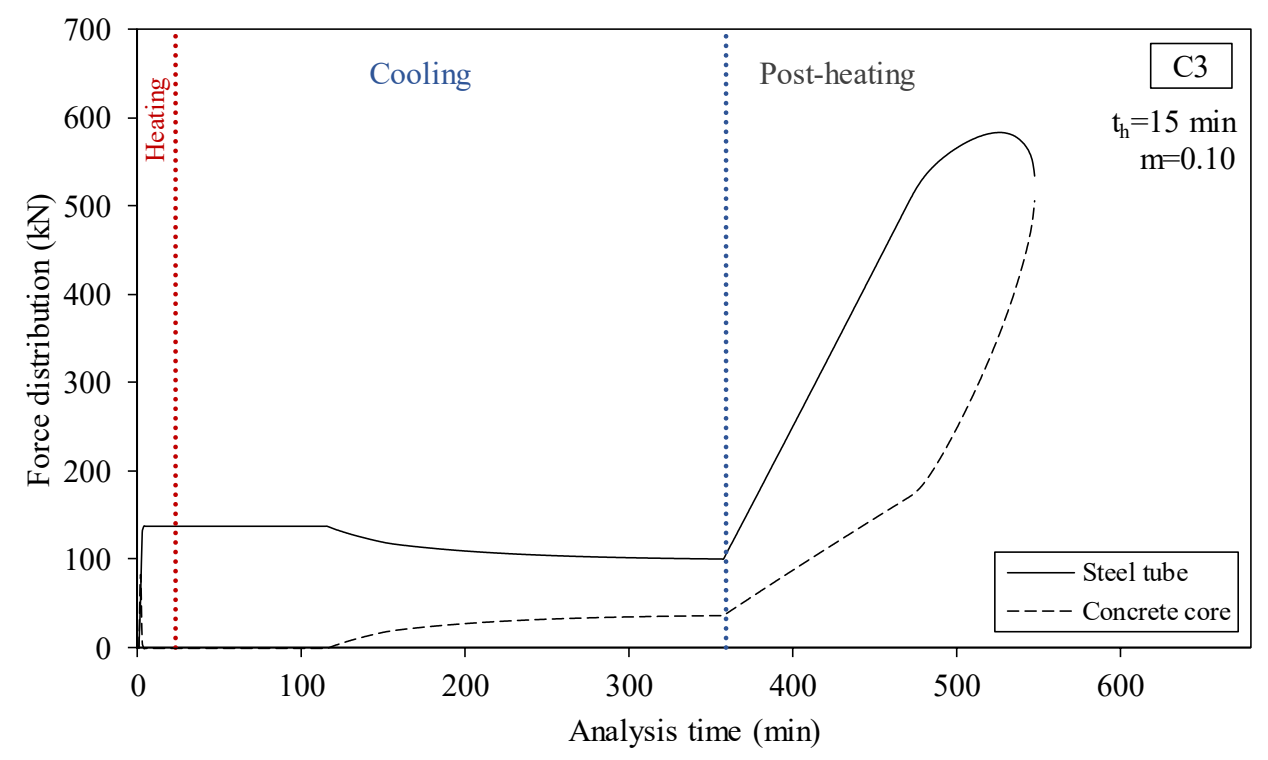

b)

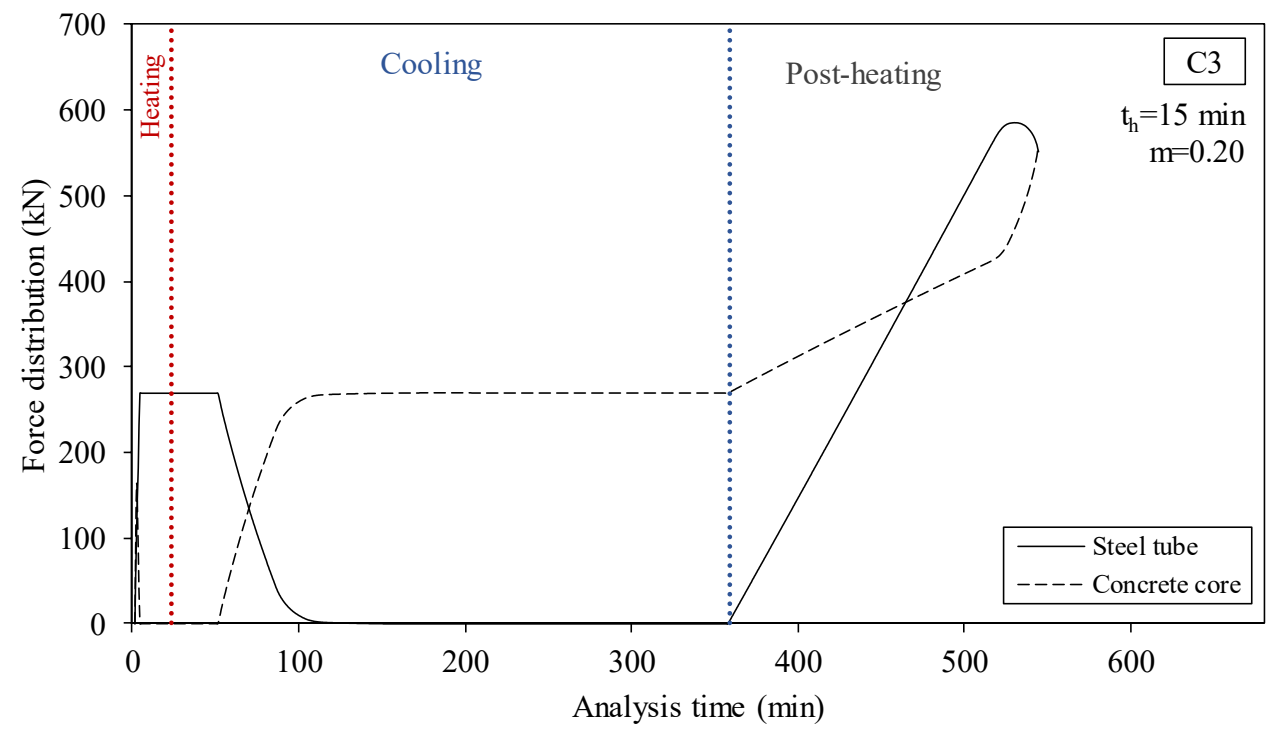

Fig. 13. Force distribution-time for specimen $C 3$ with $t_{h}=15$ minutes: a) $m=0.10$; b) $m=0.20$. 


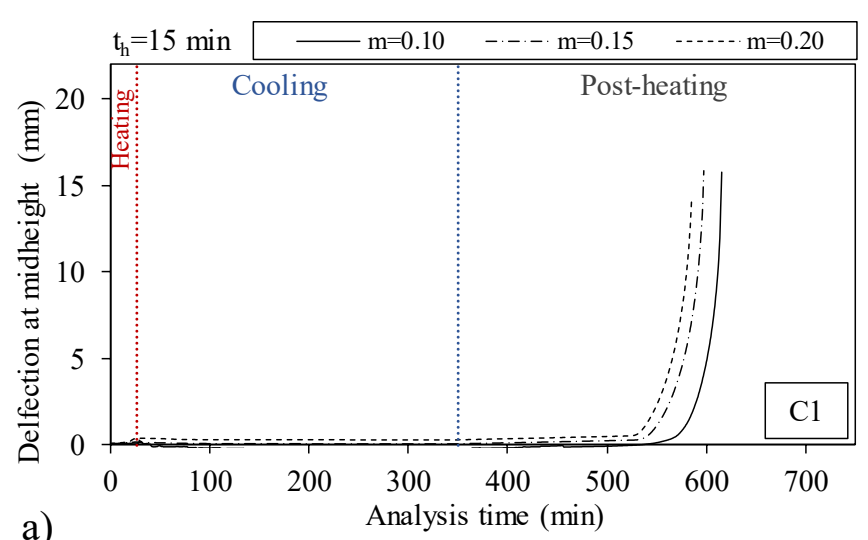

a)

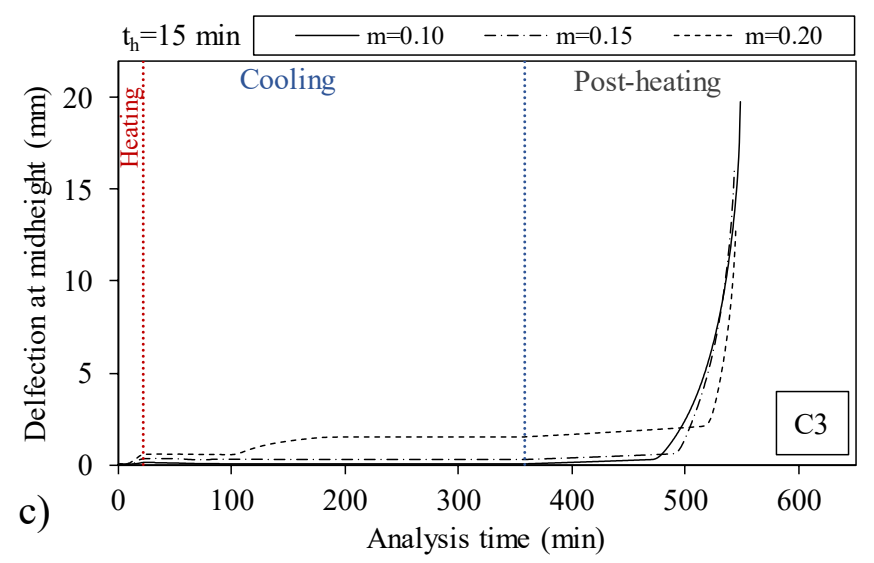

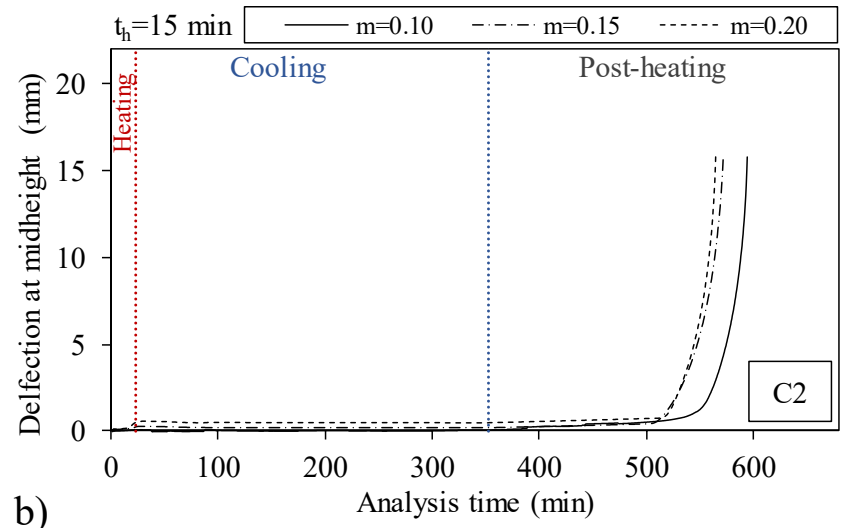

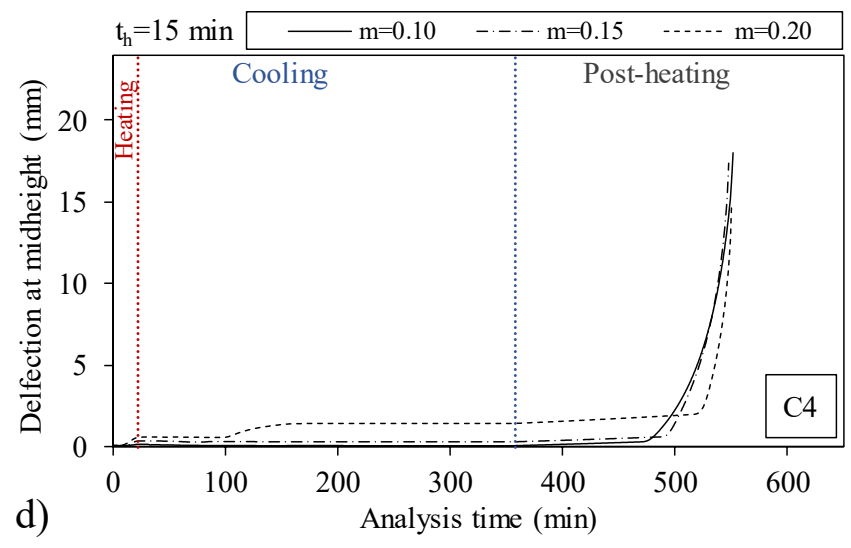

Fig. 14. Influence of load ratio on the deflection-time curves for $t_{h}=15$ minutes. 

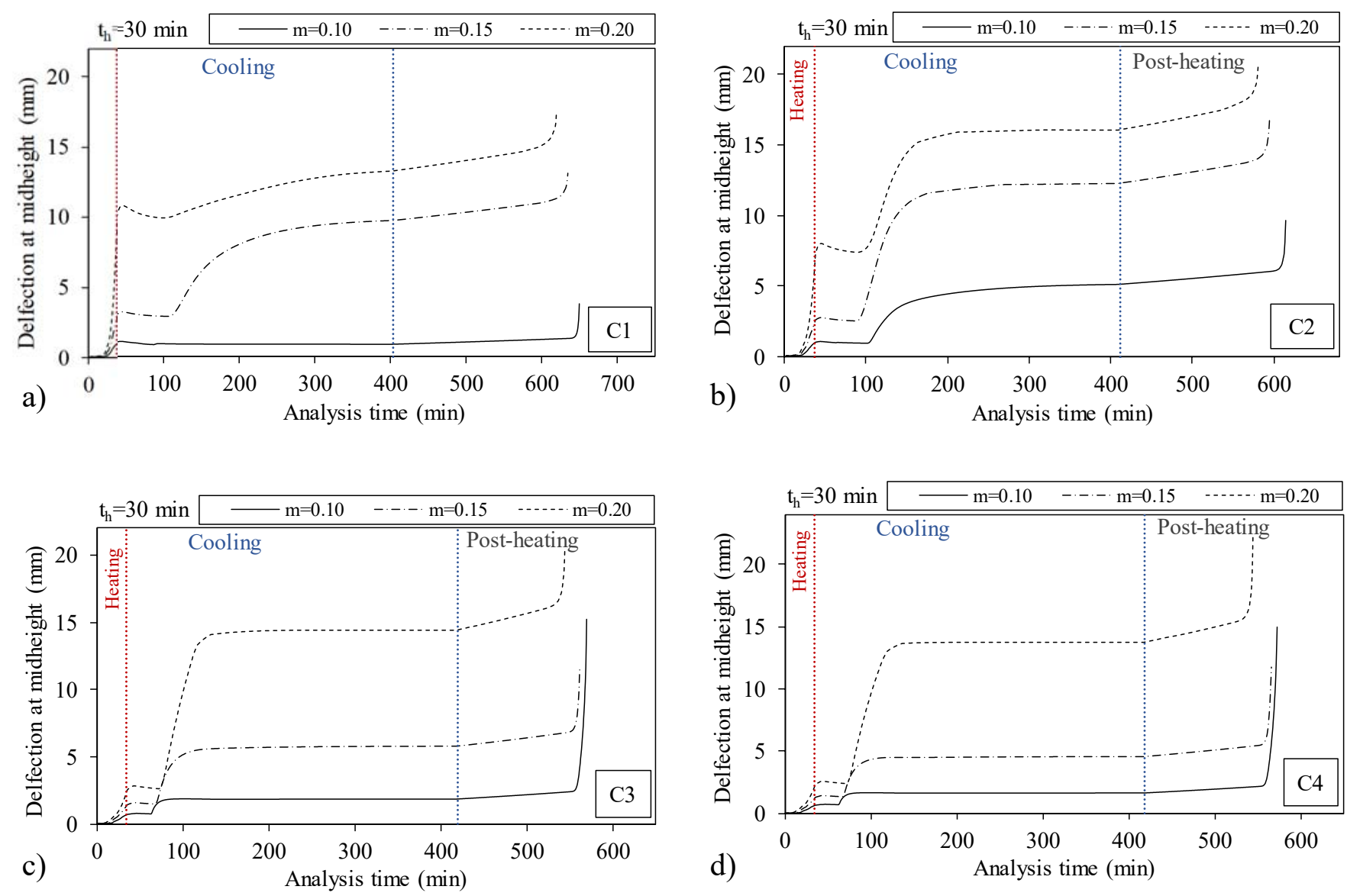

Fig. 15. Influence of load ratio on the deflection-time curves for $t_{h}=30$ minutes. 

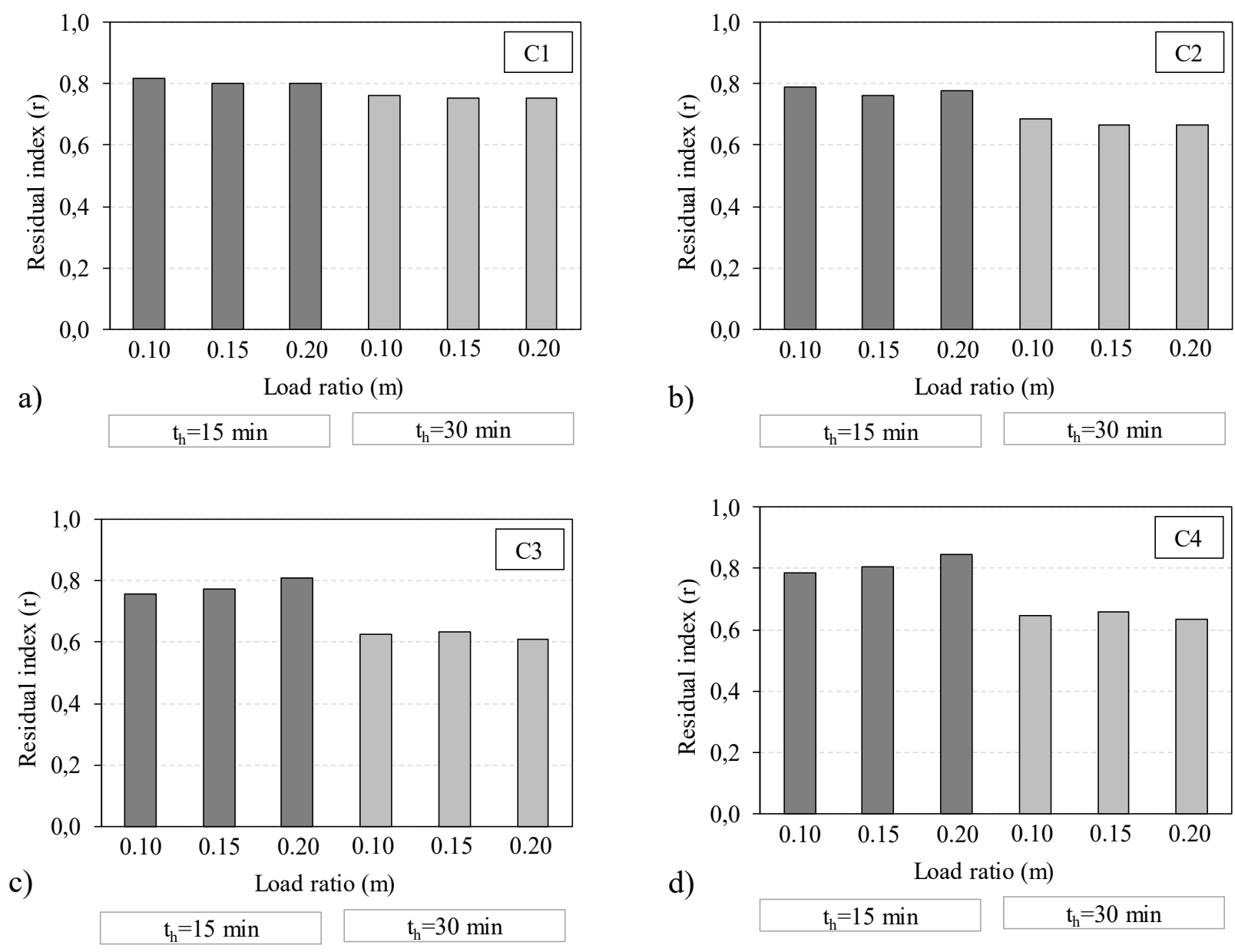

Fig. 16. Residual capacity for the columns analysed. 
Table 1. Details of the columns, test and predicted values of the residual capacity

\begin{tabular}{|c|c|c|c|c|c|c|c|c|}
\hline \multirow[b]{3}{*}{ Test } & \multirow[b]{3}{*}{$\begin{array}{c}D \\
(\mathrm{~mm})\end{array}$} & \multirow[b]{3}{*}{$\underset{(\mathbf{m m})}{t}$} & \multirow[b]{3}{*}{$\begin{array}{c}L \\
(\mathrm{~mm})\end{array}$} & \multirow[b]{3}{*}{$\begin{array}{l}\text { Steel ratio } \\
(\alpha)\end{array}$} & \multirow{3}{*}{$\begin{array}{c}\text { Test } \\
N_{\text {ambient }} \\
(\mathbf{k N})\end{array}$} & \multicolumn{2}{|c|}{ After 120 minutes of heating } & \multirow{3}{*}{$\boldsymbol{\xi}=\frac{\boldsymbol{N}_{\text {post } \text { pred }}}{\boldsymbol{N}_{\text {post,test }}}$} \\
\hline & & & & & & Test & Predicted & \\
\hline & & & & & & $\begin{array}{l}N_{\text {post }} \\
(\mathbf{k N})\end{array}$ & $\begin{array}{l}N_{\text {post }} \\
(\mathbf{k N})\end{array}$ & \\
\hline $\mathrm{C} 1$ & 139.7 & 10 & 1400 & $36 \%$ & 1772 & 1061 & 1017 & 1.04 \\
\hline $\mathrm{C} 2$ & 139.7 & 8 & 1400 & $27 \%$ & 1664 & 813 & 849 & 0.96 \\
\hline $\mathrm{C} 3$ & 139.7 & 5 & 1400 & $16 \%$ & 1372 & 591 & 552 & 1.07 \\
\hline \multirow[t]{3}{*}{$\mathrm{C} 4$} & 139.7 & 5 & 1400 & $16 \%$ & 1346 & 583 & 559 & 1.04 \\
\hline & & & & & & & Mean & 1.03 \\
\hline & & & & & & & SD & 0.05 \\
\hline
\end{tabular}

Table 2. Values of the variables in the analysis

\begin{tabular}{cc}
\hline Variable & Specified values \\
\hline$t_{h}(\min )$ & $15 ; 30$ \\
$m$ & $0.10 ; 0.15 ; 0.20$ \\
\hline
\end{tabular}




\section{LIST OF FIGURE CAPTIONS}

Fig. 1. Parallel model scheme and discretization of the section [12].

Fig. 2. Linear interpolation of yield strength of steel at cooling stage.

Fig. 3. Load-deflection curves at room temperature a) C100-5-2-60-20; b) C100-3-2-30-20 [20].

Fig. 4. Axial displacement - Time: a) C-159-6-3-30-0-20 [21]; b) C-04 [22]; c) CBL-1 [23].

Fig. 5. Temperature-time for specimen C1.

Fig. 6. Load-deflection curves at post-fire stage.

Fig. 7. Scheme of the analysis procedure.

Fig. 8. Typical load-axial displacement curve.

Fig. 9. Influence of load ratio and heating time on the load-axial displacement curves.

Fig. 10. Typical axial displacement -time curves under combined temperature and loading.

Fig. 11. Influence of load ratio on the axial displacement-time curves for $t_{h}=15$ minutes.

Fig. 12. Influence of load ratio on the axial displacement-time curves for $t_{h}=30$ minutes.

Fig. 13. Force distribution-time for specimen $\mathrm{C} 3$ with $t_{\mathrm{f}}=15$ minutes: a) $m=0.10$; b) $m=0.20$.

Fig. 14. Influence of load ratio on the deflection-time curves for $t_{h}=15$ minutes.

Fig. 15. Influence of load ratio on the deflection-time curves for $t_{h}=30$ minutes.

Fig. 16. Residual capacity for the columns analysed.

\section{LIST OF TABLE CAPTIONS}

Table 1. Details of the columns, test and predicted values of the residual capacity

Table 2. Values of the variables in the analysis 